\begin{tabular}{cc} 
Sharif University of Technology \\
Scientia Iranica \\
SCIENTIA & Transactions B: Mechanical Engineering \\
I RAN I CA & \\
\hline
\end{tabular}

\title{
The 3-D finite-element analysis of press fitting process in railway wheel-set
}

\author{
S. Sarabandi ${ }^{\mathrm{a}, *}$, H. Soleimani ${ }^{\mathrm{b}}$, and S. Mahmoudi ${ }^{\mathrm{c}}$ \\ a. Institute of Industrial and Control Engineering, Universitat Politecnica de Catalunya, Barcelona, Spain. \\ b. Department of Mechanical Engineering, Faculty of Engineering, Ferdowsi University of Mashhad, Mashhad, Iran. \\ c. Department of Mechanical Engineering, Najafabad Branch, Islamic Azad University, Najafabad, Iran.
}

Received 21 August 2017; received in revised form 30 September 2017; accepted 7 November 2017

\section{KEYWORDS}

Residual stress;

Thermal loading;

Press fitting process;

Finite element;

Railway wheel.

\begin{abstract}
Variations in the loading of rolling contact components lead to a change in contact forces between surfaces. These forces represent the main cause of rolling contact damages such as fatigue. Residual stresses represent a major issue in railway wheel structures, and it is appropriate to reduce such stresses. This paper aims to estimate residual stresses in railway wheel due to hub-to-rim and axle-to-hub fitting processes. A three-dimensional nonlinear model of stress is applied to analyze a stress field during the press fitting process. An elastic-plastic finite-element model is developed to model variable thermal loading in railway wheel. Finally, results of three-dimensional finiteelement analysis showed good agreement with field observations.
\end{abstract}

(C) 2019 Sharif University of Technology. All rights reserved.

\section{Introduction}

Wheel, rail, and weld fractures in railway structures occur due to many factors such as improper fitting during press fitting process of wheels to the axel, residual stresses in wheels, inappropriate welding quality (inadequate pre-heating, wrong adjustment of rail gaps, imbalanced temperature condition, no stress release, etc.), fatigue in wheel and rail, large impacts from faulty wheels (sharp edges and flanges), etc. The points with maximum stresses are the best choices where cracks may initiate and, consequently, propagate. For this reason, identifying these regions and calculating the amount of stresses can be very helpful in nondestructive inspection and life estimation methods.

The residual stress produced due to manufacturing procedures in railway wheel structure can vary according to mechanical stresses during the working

\footnotetext{
*. Corresponding author.

E-mail address: soh.sarabandi@gmail.com (S. Sarabandi).
}

condition. These stresses are affected by thermal operations during manufacturing process. In recent decades, different research works have been performed to estimate residual stresses. These stresses have an important role in mechanical components by removing the surface materials [1]. According to the significance of exact analysis of these forces and the effect of manufacturing residual stresses on the amount of such forces in contact areas, the application of numerical methods in this field is very important [2-5].

Okagata et al. [6] studied the fatigue strength of Japan's railway wheel and presented a fatigue design methodology for high-speed railway wheel by considering the effect of manufacturing conditions on fatigue strength of materials. In [7-13], some of these problems are solved using experimental, analytical, and finiteelement procedures. A considerable number of studies are conducted on the effect of different parameters on fatigue crack growth, such as initial crack angle and type of loading [14-16]. Masoudinejad performed a vast range of researches on the effect of residual stresses on fatigue crack propagation in wheel-rims. Shariati et al. [17] studied fatigue crack growth and 
life estimation of wheel-rims by considering the effect of contact and thermal stresses. The results of their study revealed that the crack growth in the Iranian wheel-rail structures with no residual stress contains shear modes of II and III [17-21]. Maousdinejad also investigated the stress field calculation of the manufacturing process in the wheel structure. He developed a three-dimensional elastic-plastic finite-element model to estimate the stress field. The comparison of such a stress field with experimental results of other researches led to acceptable agreement [22].

In many of the aforementioned researches, residual stresses are calculated by means of numerical simulation and a finite-element method. Unfortunately, available techniques for residual stress estimation in wheel/rail structures are quite simple. The finiteelement model requires fine and tiny mesh to reach results that are more exact. Therefore, a simple model is not able to achieve an exact stress field under the effect of thermal loads.

In this paper, a three-dimensional elastic-plastic finite-element method is applied to the real profile of railway wheel in order to anticipate stress distribution according to the press fitting process. Simulation of manufacturing process consists of two parts: nonlinear transient thermal analysis and nonlinear structural analysis.

\section{Governing equations}

Press fitting is an approach that produces residual stresses in the structure. In this approach, elastic pressure of the material is mostly used. The main challenge in this method is its high sensibility to manufacturing tolerances and its cost. The function in radial symmetry problems is defined as $F=F(r)$; thus, the equilibrium equations are as follows:

$$
\left\{\begin{array}{l}
\frac{\partial\left(h \sigma_{r}\right)}{\partial r}+\frac{1}{r} \frac{\partial\left(h \tau_{r \theta}\right)}{\partial \theta}+\frac{h\left(\sigma_{r}-\sigma_{\theta}\right)}{r}+h R=0 \\
\frac{\partial\left(h \tau_{r \theta}\right)}{\partial r}+\frac{1}{r} \frac{\partial\left(h \sigma_{\theta}\right)}{\partial \theta}+\frac{2\left(h \tau_{r \theta}\right)}{r}+h \Theta=0
\end{array}\right.
$$

Thickness $h$ is constant in Eq. (1), and its form varies as follows:

$$
\frac{d \sigma_{r}}{d r}+\frac{1}{r}\left(\sigma_{r}-\sigma_{\theta}\right)+R=0, \quad \Theta=0 .
$$

According to the nature of axisymmetric problems and due to symmetry in tangential body forces, $\Theta$ is considered as zero, and stress components of $\left(\sigma_{r}, \sigma_{\theta}\right)$ and radial body force are a function of $r$ (radius). It should also be noted that shear stress $\tau_{r \theta}$ is zero.

Thus, the equilibrium equations are presented according to the derivatives of Airy stress function as follows:

$$
\left(\frac{d^{2}}{d r^{2}}+\frac{1}{r} \frac{d}{d r}\right)\left(\frac{d^{2} F}{d r^{2}}+\frac{1}{r} \frac{d F}{d r}\right)=0 .
$$

Eq. (3) can be simplified to Eq. (4) where $F$ stress function can be obtained by a direct integration, and the obtained result is shown as in Eq. (5).

$$
\begin{aligned}
& \frac{1}{r} \frac{d}{d r}\left\{r \frac{d}{d r}\left[\frac{1}{r} \frac{d}{d r}\left(r \frac{d F}{d r}\right)\right]\right\}=0, \\
& F=A \ln r+B^{2} \ln r+C r^{2}+D
\end{aligned}
$$

where $A, B, C$, and $D$ are integration constants and can be achieved using boundary conditions. $D$ constant is not used in stress component equations because all equations depend on only the derivatives of $F$ stress function. Therefore, through substitution process in Eq. (5), stress components are achieved as follows:

$$
\begin{aligned}
& \sigma_{r}=\frac{1}{r} \frac{d F}{d r}=\frac{A}{r^{2}}+B(1+2 \ln r)+2 C, \\
& \sigma_{\theta}=\frac{d^{2} F}{d r^{2}}=-\frac{A}{r^{2}}+B(3+2 \ln r)+2 C .
\end{aligned}
$$

If $B$ is considered zero ( $B$ should be considered zero in order to achieve only one amount for displacement [6]), then the following result is obtained:

$$
\sigma_{r}=\frac{A}{r^{2}}+2 C, \quad \sigma_{\theta}=-\frac{A}{r^{2}}+2 C .
$$

Two boundary conditions are required to obtain two constants. By assuming a thick-walled pressure vessel with inner radius of a and outer radius of $b$ under internal pressure of $P_{i}$ and external pressure of $P_{e}$, the boundary conditions are as follows:

$$
\begin{gathered}
\sigma_{r}=-P_{e} \quad \Leftrightarrow \quad r=b, \\
\sigma_{r}=-P_{i} \quad \Leftrightarrow \quad r=a .
\end{gathered}
$$

Therefore,

$$
\begin{aligned}
& A=\frac{a^{2} b^{2}\left(P_{e}-P_{i}\right)}{b^{2}-a^{2}}, \\
& 2 C=\frac{P_{i} a^{2}-P_{e} b^{2}}{b^{2}-a^{2}} .
\end{aligned}
$$

By considering $P_{i}=P$ and $P_{e}=0$ and substituting Eqs. (9) and (10) into Eq. (8), the following equation is achieved:

$$
\begin{aligned}
\sigma_{r} & =-\frac{a^{2} b^{2} P}{\left(b^{2}-a^{2}\right) r^{2}}+\frac{a^{2} P}{b^{2}-a^{2}} \\
\sigma_{\theta} & =\frac{a^{2} b^{2} P}{\left(b^{2}-a^{2}\right) r^{2}}+\frac{a^{2} P}{b^{2}-a^{2}}
\end{aligned}
$$

Variations of $\left(\sigma_{r}, \sigma_{\theta}\right)$ in radial direction are shown in Figure 1. 


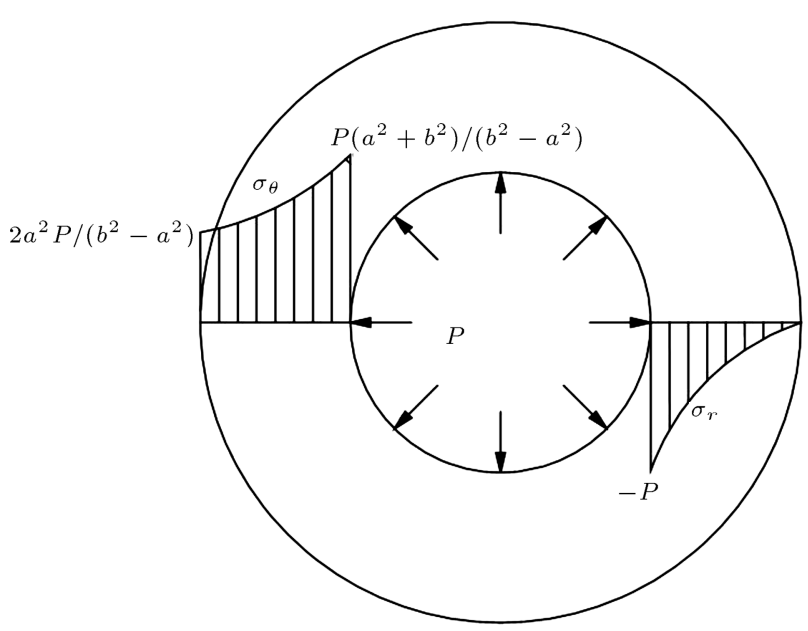

Figure 1. Stress distribution in the thickness of a thick-walled cylinder.

\section{Finite-element analysis}

Wheel wear occurs due to train motion on the rail which increases with time. Wheel has a special profile in its contact position to the rail. This profile changes in form under the effect of wear phenomenon. Thus, wheel/rail structure disassembles after a while, and a new profile is provided again by machining. Each machining process leads to a reduction in the wheel thickness up to the point of uselessness.

Therefore, under such wear condition, railway wheel is designed in two parts: (1) hub, and (2) rim. The part related to the special profile is placed in rim. The S1002 wheel profile that is applied to the Iranian railway wheel system is used for geometrical modelling of the wheel. Coordinates of 497 points are extracted from an 8-degree polynomial in order to enhance the modelling precision. Exact modelling of wheel profile is very significant due to its great effect on contact stress field of the wheel. Other parts of the wheel's cross-section are modelled by means of related standards (Figure 2). The selected wheel for this study is a rim-type wheel with $920 \mathrm{~mm}$ diameter, which is selected as a new wheel's diameter in the Iranian railway system.

In order to model the contact between hub and rim, the 0.2 friction coefficient is selected to define contact elements. In this model, a reduction in temperature causes contraction to provide an appropriate fitting process with no thermal effect on stresses. Figure 3 shows different parts of the model of wheel-rim before and after the assembly.

Material model of wheel-rim is considered as elastic-plastic behavior with linear kinematic hardening. The wheel material model is defined as homogeneous and isotropic. A stress-strain curve for different temperatures and the final model with its elements are shown in Figures 4 and 5, respectively.

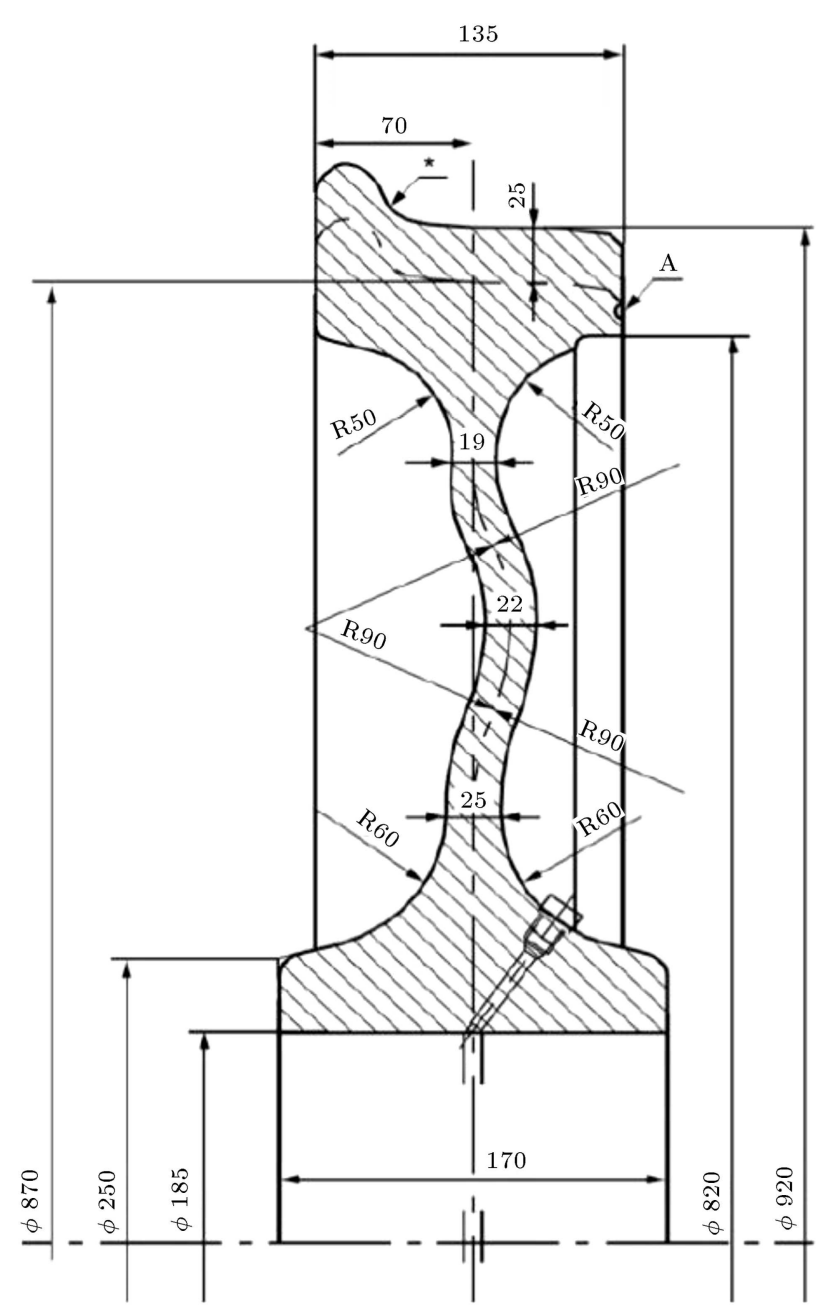

Figure 2. Geometry of a wheel-rim cross-section with a 920-mm diameter.

A manufacturing process of wheel-rim contains machining the internal surface of an old wheel in its rim part. In this step, the desired clearance fit is prepared for internal surface of rim. The next step relates to two wheels that are connected to an axle and are moved onto the rail to be mounted on a fixture for machining the outer surface of hub. In this step, clearance fit for outer surface of the hub is provided, and its surface finishing process is satisfied.

In a practical application, the rim is put into the oven in order to fit the hub. Heating is applied using an electromagnetic induction method. The coils, placed around the rim, cause an electromagnetic field and provide the required heat. In wheel-rim manufacturing, hub is fitted directly to the axle. The maximum radial clearance fit between hub and axle after fitting process is $0.15 \mathrm{~mm}$. Subsequently, the rim is fitted to the hub by means of a thermal method. In this method, the rim is placed in a position and will be expanded due to heating treatment, and its inner radius increases. Then, it is placed on the hub that releases the heat with time and is fixed on the hub. 


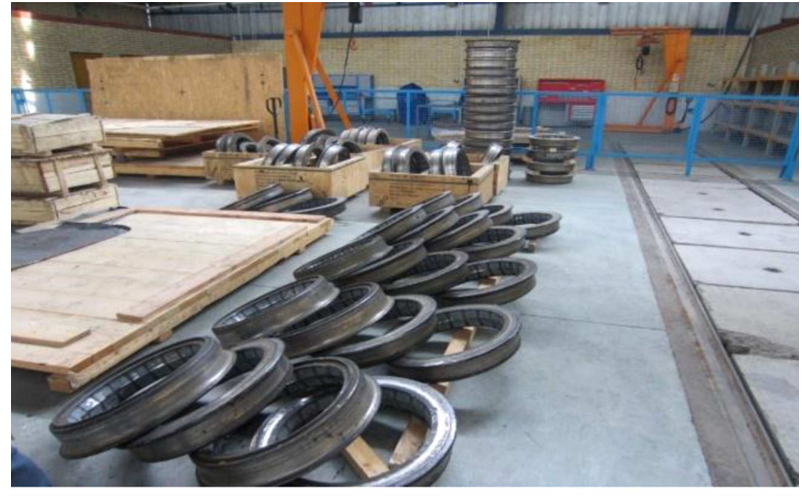

(a)

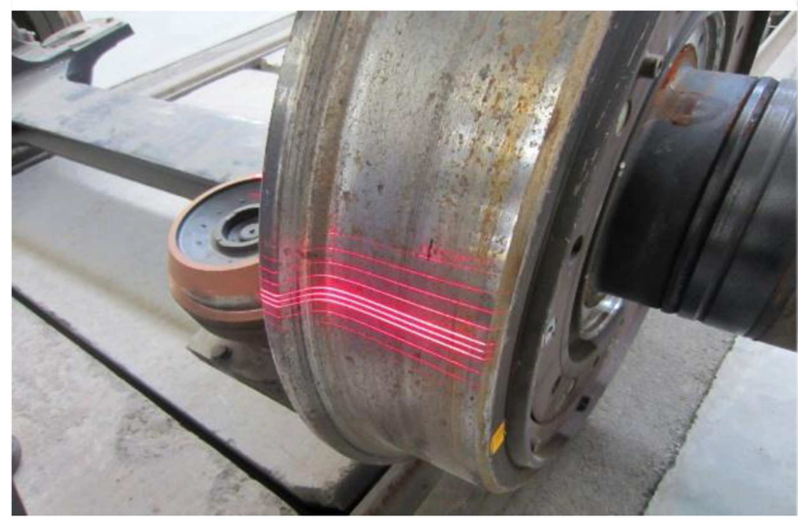

(b)

Figure 3. Different parts of wheel-rim before and after assembly: (a) Field observations before assembly and (b) field observation after assembly.

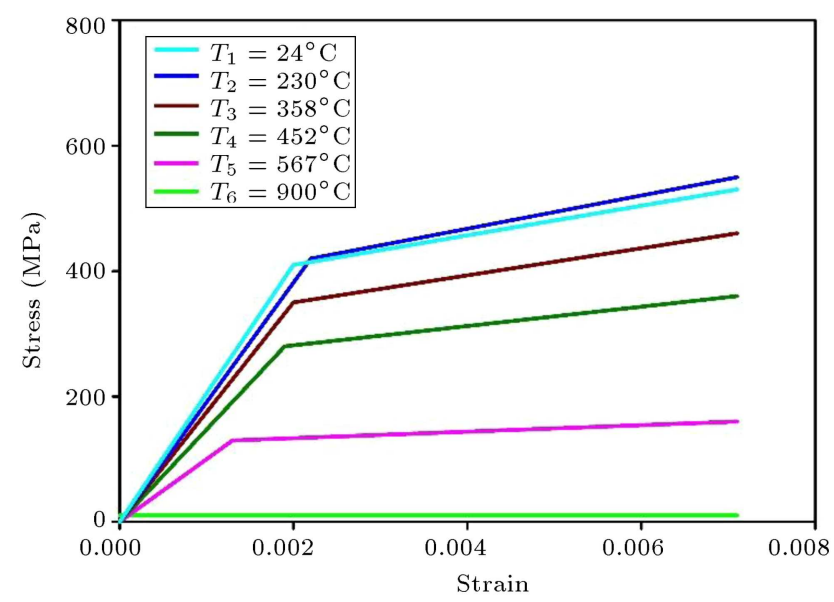

Figure 4. Temperature-dependent stress-strain data applied to the simulation of thermal treatment of wheel [18].

The maximum radial clearance fit between rim and hub is $0.75 \mathrm{~mm}$. Clearance fits are applied by thermal expansion method and do not have any effect on stress solution. Temperature of the rim is controlled by thermo-meters (with maximum allowable temperature of 250 centigrade degrees), and the oven will be turned

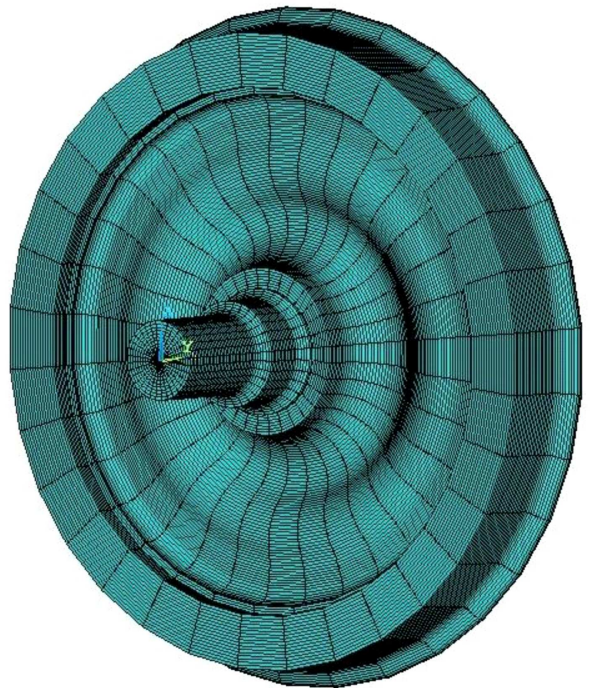

Figure 5. Elements of wheel-rim model.

off after ensuring that a complete fitting has occurred between hub and rim. It can be concluded that, in such a manufacturing procedure, only the rim is departed from the hub after passing all allowable exfoliations and, consequently, only the rim is replaced and hub remains on axle. This method saves significant material and time and is very cost effective.

Considerable parts of passenger wagon wheels are of rim types. Tolerance of fitting the rim and hub produces a pressure between these two parts, and such a fitting pressure is the cause of static friction force between hub and rim. The static friction force prevents relative movement of rim on the hub during working condition. There are different parameters that reduce this force and increase the possibility of rim slide on hub, such as manufacturing and assembling factors (surface roughness, clearance fit, surface alignment, etc.) and working factors (breaking using break shoe). An inner diameter of rim is measured using a micrometer in workshop that can be 1.1 to $1.5 \mathrm{~mm}$ lower than the outer diameter of the hub. Displacement in the direction of wheel motion is considered as zero, and the fitting process of thermal contraction is considered with no effect on stresses.

After heating the rim up to a specified temperature, hub is placed in the rim from the top position through a high-precision machine. Following the conductance of initial fitting process, it takes time for these parts to release their heat. During the cooling step, rim and hub contact surfaces apply high pressure to each other, hence inducing stresses in these regions. Finally, after mounting the rim on the hub, a ring is put around the hub in order to prevent the rim movement from one side of the hub. This ring will not depart from the wheel until the rim functions properly. The process of mounting the ring contains two main parts: at first, a part of the ring is placed on a step, and then 
by moving the rim and hub, other parts of the ring are mounted on the step.

The required parameters for heat transfer analysis contain thermal conductivity and specific heat. Thermal conductivity $(k)$ is defined as the ability of material to transfer thermal energy by conduction that is a transitive property, and its unit is $\mathrm{W} / \mathrm{m}^{\circ} \mathrm{C}$. Temperature-dependent mechanical properties of steel wheel are estimated. In addition, data are required to define Young modulus $(E)$, Poisson's ratio $(v)$, thermal expansion coefficient $(\alpha)$, and stress-strain relations in different temperatures in order to achieve stresses in structural analysis. Such parameters are defined as inputs of finite-element analysis. Stress-strain curves in different temperatures are shown in Figure 4.

\section{Results and discussion}

Maximum and minimum thicknesses of the rim are considered as 75 and $35 \mathrm{~mm}$, respectively. In the present analysis, radial clearance fit between hub and rim is defined as 0.75 and $0.35 \mathrm{~mm}$ in its maximum and minimum modes, respectively. The friction coefficient is also selected as 0.4 for the highest value and 0.1 for its lowest value. The maximum value of clearance fit between hub and axle is set as $0.15 \mathrm{~mm}$. Radial and Von-Mises stresses in contact area of hub and rim (fitting pressure) are calculated for each of the aforementioned cases. The required moment for sliding the rim on hub can be achieved by fitting pressure and friction coefficient.

Results of the rim modelling with maximum thickness of $75 \mathrm{~mm}$ and maximum friction coefficient of 0.4 and different clearance fit values (the maximum is selected as $0.75 \mathrm{~mm}$ and the minimum is $0.375 \mathrm{~mm}$ ) are shown in Figures 6 to 8 . Fitting pressure or the pressure between rim and hub is calculated from radial stresses between rim and hub. This pressure is not uniform and can also be calculated for different friction coefficients and clearance fits between hub and rim. The corresponding results are shown in Figure 9.
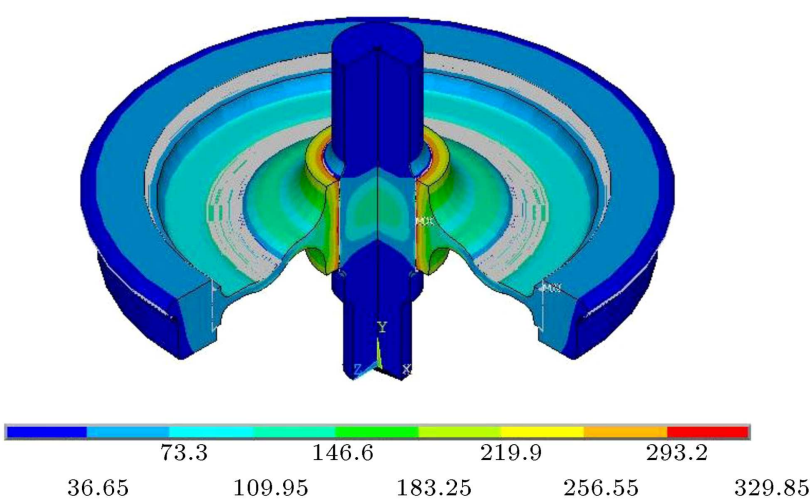

Figure 6. Von-Mises stress for radial clearance fit of $0.75 \mathrm{~mm}$.
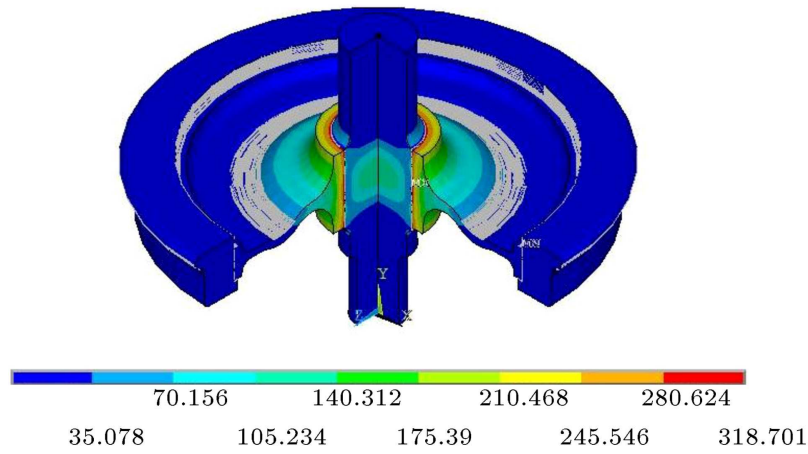

Figure 7. Von-Mises stress for radial clearance fit of $0.5 \mathrm{~mm}$.
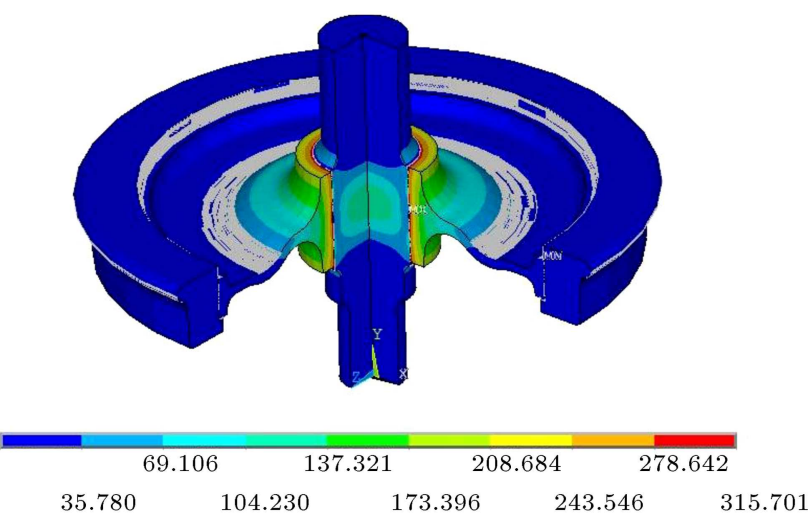

Figure 8. Von-Mises stress for radial clearance fit of $0.4 \mathrm{~mm}$.

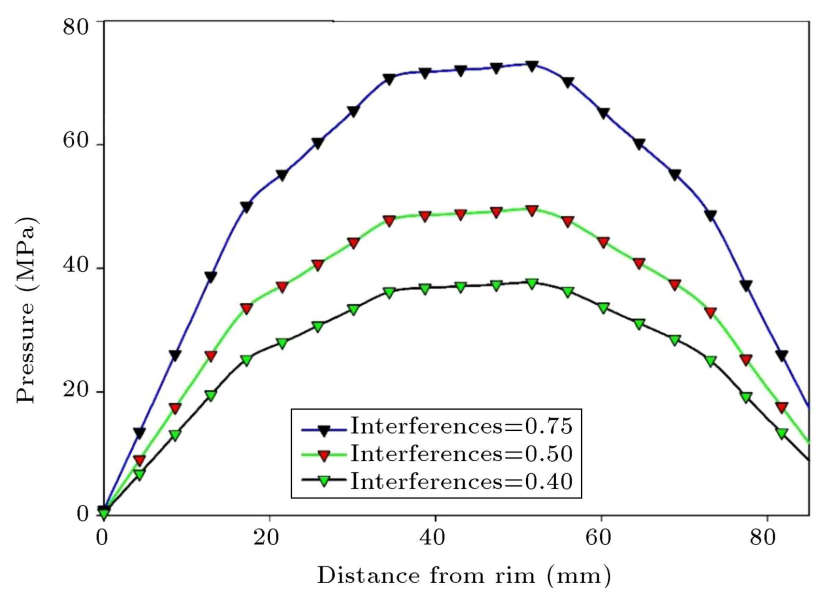

Figure 9. Fitting pressure for different clearance fit values.

Results of rim modelling with $75 \mathrm{~mm}$ thickness and 0.3 friction coefficient and by considering different values for clearance fit are shown in Figures 10 to 12 . Fitting pressure (the pressure between rim and hub) is calculated from radial stresses that are present between contact surfaces of rim and hub. Fitting pressure values for different clearance fits, $75 \mathrm{~mm}$ rim thickness, and 0.3 friction coefficient are shown in Figure 13.

Von-Mises stress results of a $75 \mathrm{~mm}$ thickness rim, 0.2 friction coefficient, and different clearance fit values 

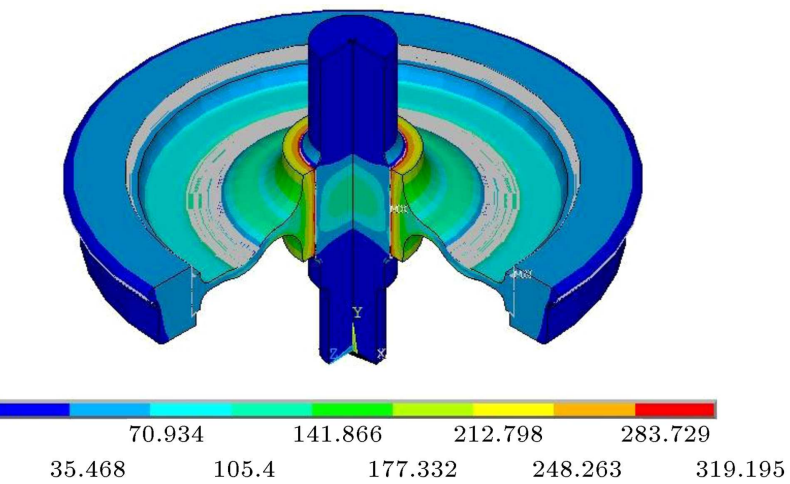

Figure 10. Von-Mises stress for radial clearance fit of $0.75 \mathrm{~mm}$.
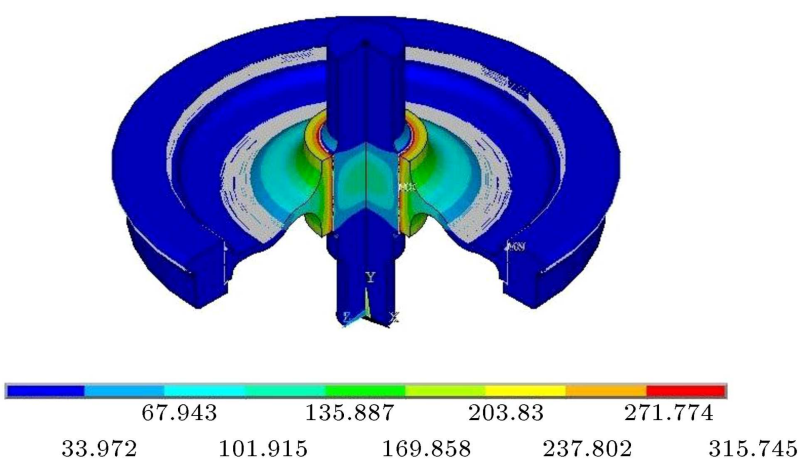

Figure 11. Von-Mises stress for radial clearance fit of $0.5 \mathrm{~mm}$.
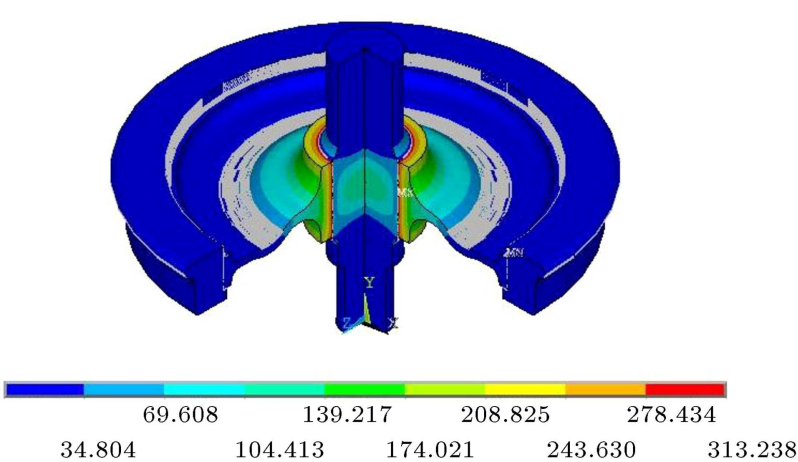

Figure 12. Von-Mises stress for radial clearance fit of $0.4 \mathrm{~mm}$.

are shown in Figures 14 to 16. Fitting pressures for the same rim thickness, friction coefficient, and clearance fit values are also shown in Figure 17. It can be inferred that the Von-Mises stress increases as clearance fit and fitting pressure increase. The Von-Mises stress also decreases by reducing the friction coefficient between rim and hub.

\section{Conclusion}

In this paper, a three-dimensional finite-element analysis study was carried out in order to simulate residual stresses in a wheel-rim and develop the residual stress

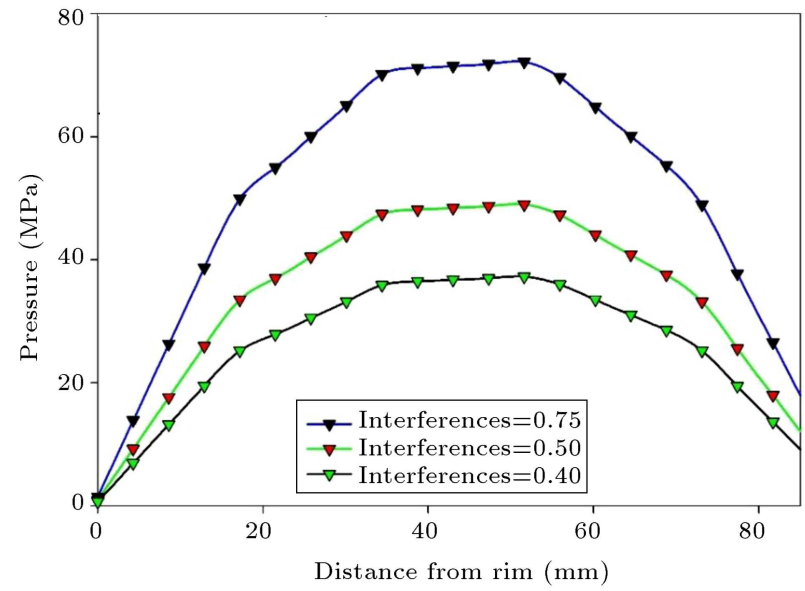

Figure 13. Fitting pressure for different radial clearance fit values.
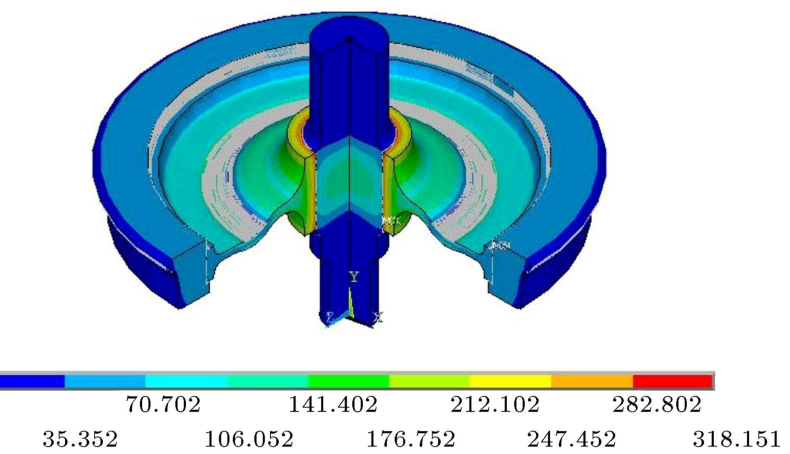

Figure 14. Von-Mises stress for radial clearance fit of $0.75 \mathrm{~mm}$.

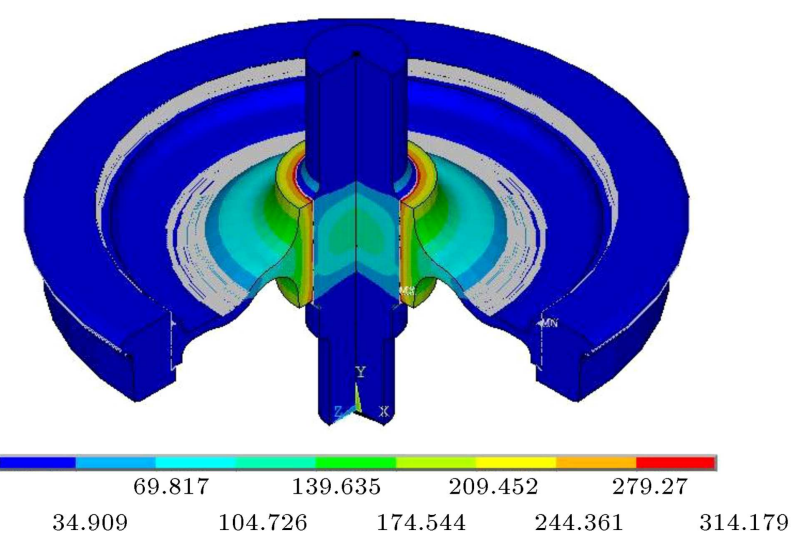

Figure 15. Von-Mises stress for radial clearance fit of $0.5 \mathrm{~mm}$.

of fitting process. Three-dimensional nonlinear finiteelement analysis was applied to calculate residual stresses. Clearance fit between hub and rim created a pressure between their contact areas, preventing the rim to slide on hub. Such clearance fit was provided by variable thermal loading steps. Different parameters lead to a reduction in friction coefficient and an increase in the likelihood of rim slid on hub. These factors consist of manufacturing and assembly parameters 

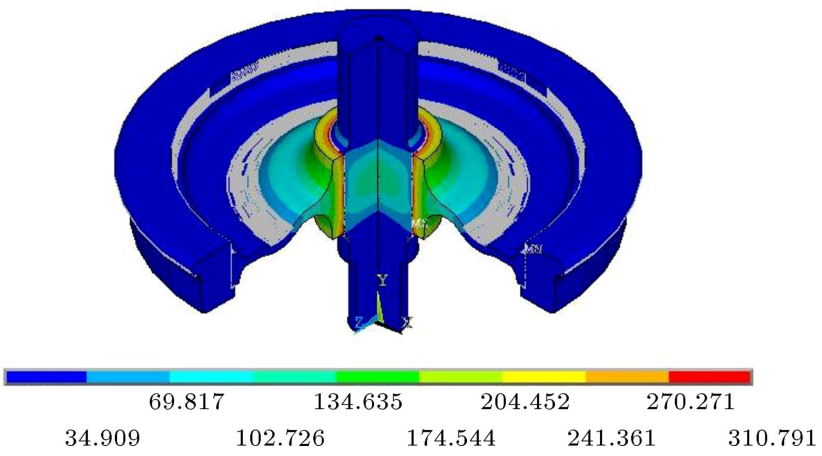

Figure 16. Von-Mises stress for radial clearance fit of $0.4 \mathrm{~mm}$.

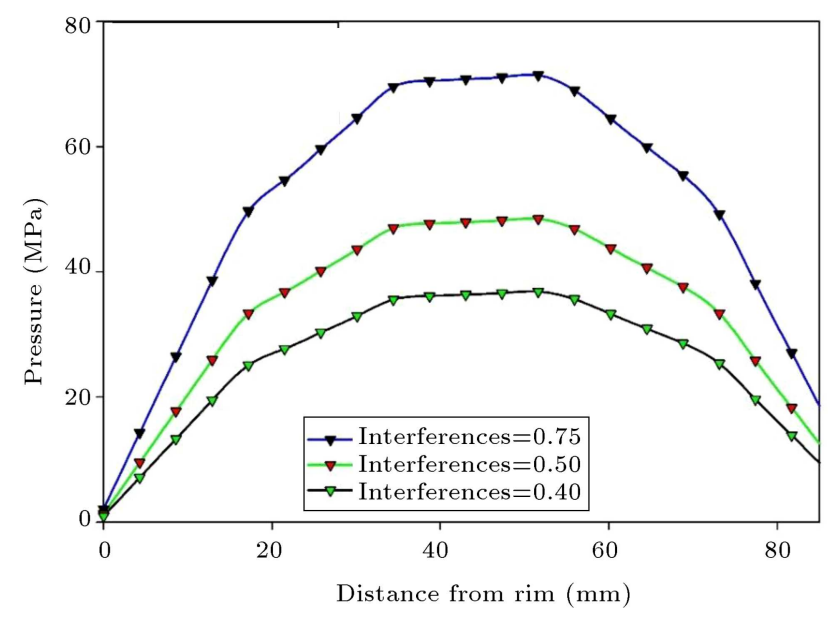

Figure 17. Fitting pressure for different radial clearance fit values.

(clearance fit and surface roughness) and operation parameters (mechanical residual stresses). According to the performed analysis, friction coefficient does not have any considerable effect on fitting pressure and fatigue life. Therefore, surface roughness that is in a direct relation to friction coefficient has no effect on radial clearance fit. Finally, the following conclusions can be inferred from results of this paper:

1. Results of finite-element analysis show that the stress distribution is very important and high stress level has significant effect on crack initiation;

2. Results revealed that stress is very sensitive to thermal loading. Therefore, this parameter has considerable effect on thermal treatment process of railway wheel;

3. Circumferential stress results of the wheel confirm that these amounts are effective in crack initiation until the stress values has high values;

4. It can be inferred from the results that if the clearance fits are exactly observed, the friction force between wheel and rail will not be able to cause rim slide on hub;

5. Friction coefficient does not have considerable effect on fitting pressure; consequently, variations in surface roughness do not have direct effect on friction coefficient and rim slide.

In this paper, residual stresses in railway wheel were estimated through fitting process. The next researchers need to consider interaction of other parameters and study the effect of parameters such as process type, boundary conditions, and material properties in railway wheel field.

\section{References}

1. Hadipour, M., Alambeigi, F., Hosseini, R., and Masoudinejad, R. "A study on the vibrational effects of adding an auxiliary chassis to a 6-ton truck", Journal of American Science, 7(6), pp. 1219-1226 (2011).

2. Masoudi Nejad, R., Farhangdoost, K.H., and Shariati, M. "Numerical study on fatigue crack growth in railway wheels under the influence of residual stresses", Engineering Failure Analysis, 52, pp. 75-89 (2015).

3. Masoudi Nejad, R. "Using three-dimensional finite element analysis for simulation of residual stresses in railway wheels", Engineering Failure Analysis, 45, pp. 449-455 (2014).

4. Salehi, S.M., Farrahi, G.H., Sohrabpoor, S., and Masoudi Nejad, R. "Life Estimation in the Railway Wheels under the Influence of Residual Stress Field", International Journal of Railway Research, 1(1), pp. 53-60 (2014).

5. Ghahremani Moghadam, D., Farhangdoost, K.h., and Masoudi Nejad, R. "Microstructure and Residual Stress Distributions Under the Influence of Welding Speed in Friction Stir Welded 2024 Aluminum Alloy", Metallurgical and Materials Transactions B, 47(3), pp. 2048-2062 (2016).

6. Okagata, Y., Kiriyama, K., and Kato, T. "Fatigue strength evaluation of the Japanese railway wheel", Fatigue Fract Eng Mater Struct., 30, pp. 356-371 (2007).

7. Siva, N.L. and Bernard, K. "Prediction of residual stresses in low carbon bainitic-martensitic railway wheels using heat transfer coefficients derived from quenching experiments", Computational Materials Science, 77, pp. 153-160 (2013).

8. Siva, N. and Bernard, K. "Thermo-mechanical modelling of residual stresses induced by martensitic phase transformation and cooling during quenching of railway wheels", Journal of Materials Processing Technology, 211(9), pp. 1547-1552 (2011).

9. Lin, K.Y. and Huang, J.S. "Analysis of residual stresses in railroad car wheels based on destructive test measumenents", Theoretical and Applied Fracture Mechanics, 12(1), pp. 73-86 (1989).

10. Moyar, G.J. "An analysis of the thermal contributions to railway wheel shelling", Wear, 144(1-2), pp. 117138 (1991). 
11. Shen, X.H., Yan, J., Zhang, L., Gao, L., and Zhang, J. "Austenite grain size evolution in railway wheel during multi-stage forging processes", Journal of Iron and Steel Research, 20(3), pp. 57-65 (2013).

12. Seo, J.W., Kwon, S.J., Jun, H.K., and Lee, D.H. "Effects of residual stress and shape of web plate on the fatigue life of railway wheels", Engineering Failure Analysis, 16(7), pp. 2493-2507 (2009).

13. Tawfik, D., Mutton, P.J., and Chiu, W.K. "Experimental and numerical investigations: Alleviating tensile residual stresses in flash-butt welds by localized rapid post-weld heat treatment", Journal of Materials Processing Technology, 196(1-3), pp. 279-291 (2008).

14. Masoudi Nejad, R., Farhangdoost, K.h., and Shariati, M. "Three-dimensional simulation of rolling contact fatigue crack growth in UIC60 rails", Tribology Transactions, 59(6), pp. 1059-1069 (2016).

15. Masoudi Nejad, R., Farhangdoost, K.h., Shariati, M., Moavenian, M. "Stress intensity factors evaluation for rolling contact fatigue cracks in rails", Tribology Transactions, 60(4), pp. 645-652 (2016).

16. Shariati, M. and Masoudi Nejad, R. "Fatigue strength and fatigue fracture mechanism for spot welds in Ushape specimens", Latin American Journal of Solids and Structures, 13(15), pp. 2787-2801 (2016).

17. Shariati, M., Mohammadi, E., and Masoudi Nejad, R. "Effect of a new specimen size on fatigue crack growth behavior in thick-walled pressure vessels", International Journal of Pressure Vessels and Piping, 150, pp. 1-10 (2017).

18. Masoudi Nejad, R. "Rolling contact fatigue analysis under influence of residual stresses", MS Thesis, Sharif University of Technology, School of Mechanical Engineering (2013).

19. Masoudi Nejad, R., Salehi, S.M., Farrahi, G.H. "Simulation of railroad crack growth life under the influence of combination mechanical contact and thermal loads", in 3rd International Conference on Recent Advances in Railway Engineering, Iran (2013).
20. Masoudi Nejad, R., Salehi, S.M., Farrahi, G.H., and Chamani, M. "Simulation of crack propagation of fatigue in Iran rail road wheels and effect of residual stresses", In: Proceedings of the 21st International Conference on Mechanical Engineering, Iran (2013).

21. Masoudi Nejad, R., Shariati, M., and Farhangdoost, K.H. "3D finite element simulation of residual stresses in UIC60 rails during the quenching process", Thermal Science, 21(3), pp. 1301-1307 (2017).

22. Masoudi Nejad, R., Shariati, M., and Farhangdoost, K.H., "Effect of wear on rolling contact fatigue crack growth in rails", Tribology International, 94, pp. 118125 (2016).

\section{Biographies}

Soheil Sarabandi received the MSc degree from Ferdowsi University of Mashhad, Iran. He is currently a PhD student in Automatic Control, Robotics and Computer Vision, Universitat Politécnica de Catalunya (UPC), Barcelona, Spain. His research interests are in the areas of finite element, motion design, kinematics \& Dynamics of robot.

Hesam Soleimani obtained his MSc degree from Ferdowsi University of Mashhad. He was a member of Mashhad Urban and Suburban Railway Operation Company (MUSROC) and worked on wheel/rail wear mechanism. He is an expert in this field now and works on the same projects.

Saeed Mahmoudi was born in 1988 in Najafabad, Iran. He graduated from Islamic Azad University, Najafabad Branch with a Mechanical Engineering BS degree. He obtained his MS degree in Mechanical Engineering from Islamic Azad University, Najafabad Branch. Currently, he is furthering his Mechanical Engineering education at Islamic Azad University, Najafabad Branch as a PhD candidate. 